WHATEVER HAPPENED TO CURRICULUM THEORY? CRITICAL REALISM AND CURRICULUM CHANGE.

\author{
Mark Priestley \\ The Stirling Institute of Education \\ University of Stirling \\ Stirling FK9 4LA \\ Tel - 01786466272 \\ Email- m.r.priestley@stir.ac.uk
}




\title{
WHATEVER HAPPENED TO CURRICULUM THEORY? CRITICAL REALISM AND CURRICULUM CHANGE.
}

\begin{abstract}
In the face of what has been characterised as a 'crisis' in curriculum - an apparent decline of some aspects of curriculum studies combined with the emergence of new types of national curriculum which downgrade knowledge some writers have been arguing for the use of realist theory to address these issues. This paper offers a contribution to this debate, drawing upon critical realism, and especially upon the social theory of Margaret Archer. The paper first outlines the supposed crisis in curriculum, before providing an overview of some of the key tenets of critical realism. The paper concludes by speculating on how critical realism may offer new ways of thinking to inform policy and practice in a key curricular problematic. This is the issue of curriculum change.
\end{abstract}

Keywords: curriculum; critical realism; curriculum change; curriculum theory.

\section{Introduction}

There is an emerging view that we face a 'crisis' of curriculum (Wheelahan 2010). While such rhetoric may be overblown, there is some validity in the notion that curriculum theory and practice are faced by new uncertainties, and that such uncertainties require new approaches to practice, and new ways of thinking. There are two major facets of this situation. The first concerns the recent emergence in curriculum policy around the world of new models of national curriculum. Such curricula are characterised by various common features, notably a structural basis in outcomes sequenced into linear levels, and a focus on generic skills or capacities instead of a detailed specification of knowledge/content. As such, they have been criticised for stripping knowledge out of the curriculum (Young 2008; Priestley 2010; Wheelahan 2010). The second facet of this crisis lies in the response of the academic community to these recent developments. It may be argued that the field of curriculum studies, at least in the UK, has declined in both status and practice in the universities and in the wider educational community (Moore 2006; Priestley and Humes 2010). This has important knock-on effects in terms of the capacity of policy 
makers and practitioners to deal with practical curriculum problems, at both the macro level of policy formation and at the meso/micro levels implementation in local authorities, curriculum agencies and schools.

This paper is, in part, a response to this supposed 'crisis' of curriculum. I first briefly explore emerging curricular trends (bearing in mind that a full analysis is beyond the scope of this paper). I suggest that, at a time when there has been an apparent decline in the application of curriculum theory to the emergence of new forms of curriculum, robust theory is badly needed to critique and address issues arising from the new curricula. These new curricula tend to be theoretically agnostic (Priestley and Humes 2010) and thus often ridden with contradictions, with the resulting further potential for negative impact on curricular practices in schools and other institutions. The remainder of the article makes the case for the use of a particular set of theories, underpinned by the philosophy of critical realism, to address curricular issues. I first outline the key tenets of critical realism, then explore the potential of such theory to address a particular key curriculum problematic, the issue of how teachers might constructively engage with policy promoting curriculum change.

\section{The 'crisis' of curriculum}

\section{A new breed of curriculum}

The last ten years have witnessed the development of a new breed of national curriculum, at least across the Anglophone world. Scotland's Curriculum for Excellence ( $\mathrm{CfE})$, while exhibiting some idiosyncratic features, is fairly typical of this policy trajectory. The New Zealand Curriculum and recent changes to England's National Curriculum provide parallel examples of this emergence of a set of common trends in curriculum prescription. Many such curricula seek to combine what is claimed to be the best features of top-down and bottom-up approaches to curriculum planning. Their architects claim that they provide both central guidance for schools (thus ensuring the maintenance of national standards), and sufficient flexibility for schools and teachers to take account of local needs in designing programmes of education. The following extract, from the Ministerial Response to the 2004 Curriculum for Excellence proposals, typifies this approach: 
Schools and education authorities will continue to be accountable for the decisions they take about the curriculum they offer, with expectations that they will use arrangements creatively and flexibly and in ways which raise levels of achievement and attainment for all young people. (Scottish Executive 2004, 10)

Contemporary curriculum policy manifests a set of inter-related trends or features. Some of these have been identified by Michael Young $(2009,1)$ : 'the introduction of National Qualifications Frameworks; the shift to learning outcomes; and the move from subject specific to generic curriculum criteria'. I do not propose to comment here on the first trend, as it is largely tangential to the arguments that I will pursue in this paper. However, the second and third trends are highly relevant to these arguments, and moreover in combination have the potential to generate some quite interesting consequences as curriculum policy is translated into practice in schools and colleges. As such, they merit further exploration here.

The outcomes tend to be predicated on what students are able to experience in their learning and/or do as a result of such learning. The following examples from the science curricula in New Zealand (Ministry of Education 2010) and Scotland (LTScotland 2010) provide a flavour of this approach:

Students will recognise that there are life processes common to all living things and that these occur in different ways. (Level 4, Life Processes, New Zealand Science Curriculum)

I can sample and identify living things from different habitats to compare their biodiversity and can suggest reasons for their distribution. (Third level, Biodiversity and Interdependence, Scotland's Curriculum for Excellence)

These outcomes exemplify an approach which has stripped knowledge from the curriculum (Young 2008), placing a new emphasis instead on generic skills. According to Moore and Young $(2001,445)$, at a time when 'we are (or soon will be) in a 'knowledge society' and .... more jobs require people to be 'knowledge workers' .... government policy documents have been remarkably silent about what this knowledge is'. 
It has been argued (Moore and Young 2001; Wheelahan 2010) that this model is driven by a narrow instrumentalism based upon economic imperatives - in other words soft skills required for the workplace rather than the sorts of powerful knowledge required to critically engage with the world. Moreover, the new curriculum models (Young 2008; Wheelahan 2010) fail to differentiate between theoretical and everyday knowledge, depriving students of a basis to develop and critique disciplinary knowledge.

Linked to the stripping out of knowledge/content from curricular outcomes, is the framing of the new curricula around capacities or core/key competencies. Thus, for example, Scotland specifies that the curriculum should enable young people to become:

- Successful learners

- Confident individuals

- Responsible citizens

- Effective contributors.

Similarly, England's revised National Curriculum posits three of the above as its curricular aims, omitting Effective Contributors. Conversely, New Zealand has adopted slightly different language in its Key Competencies, although the generic tone is similar: Thinking; Using Language, Symbols and Texts; Managing Self, Relating to Others; and Participating and Contributing.

Such capacities are redolent of the broad educational purposes articulated as the core of process curricula in former years (Stenhouse 1975; Kelly 1999), but have been criticised in their modern form. According to Wheelahan (2010) their adoption is part of a process whereby neo-liberal discourses have appropriated the language of progressive education, while maintaining technical-instrumental goals for education. Biesta (2008) has suggested that such capacities reflect a narrow, individualistic/psychological view of the learner, which misses important educational purposes, constructing citizenship as being about personal responsibility rather than, for example, political activism. On similar social control theme, Watson (2010, 99), suggests that Scotland's new curriculum 'is concerned with setting out not what children are expected to know, but how they should be'. Young $(2009,4)$ has 
questioned whether such generic skills can indeed be developed free of contextual knowledge and 'free of the domains in which they are realised'. A further criticism, based largely at present on anecdotal evidence, concerns the translation of such outcomes into educational practice in schools and college. There is some emerging evidence in Scotland (Priestley 2010) that placing this particular type of generic outcome at the sharp end of curriculum development encourages a particular type of instrumental approach to curriculum practice. This is an approach which neglects systematic attention to the processes by which curriculum policy is enacted into practice, instead focusing on how existing patterns of practice may be tweaked to fit with the new outcomes. The likely result of such engagement is what Cuban (1988) terms first order changes; modifications to epiphenomenal features of schooling, such as paperwork and procedures, with an emphasis on improving the efficiency of existing structures, mechanisms and social practices. Such changes contrast sharply with the model of transformational change that is clearly espoused by many of the new curricula; arguably second order changes to the fundamental structures, mechanisms and social practices that comprise the 'core of schooling' (Elmore 2004).

A further common trend in curriculum design (in addition to, but linked to those identified by Young) concerns the positioning of the learner at the heart of schooling. New Zealand is typical of this trend. Curriculum guidance issued in 2009 makes the following statements, the tone of which will be familiar to readers elsewhere.

If the standards and the curriculum are to make a difference for students, we need to keep each learner and their learning at the centre of all levels of decision making.

It's also important for teachers to focus on increasing their students' capacity to learn. How successful students are in achieving goals that matter to them depends on a positive disposition towards learning and on being able to think critically, manage themselves, set goals, overcome obstacles, and get along with others. Active involvement in the assessment of their learning is a key to this. (Ministry of Education 2009)

Biesta (2009) refers to this trend as the 'learnification' of education. According to Biesta, this tendency reflects an unproblematised acceptance that learning is a good 
and a failure to address educational questions such as 'what are we learning?' and 'why are we learning it?'.

Finally, the new curriculum models come packaged in proselytizing rhetoric that should be of concern in an era when teacher autonomy and professionalism have been deeply eroded by managerial forms of quality improvement (Smyth and Shacklock 1998; Ball 2008) and outcomes steering (Biesta 2004), and especially given that these new curricula purport to re-establish teacher autonomy in curriculum making. The following extract, which appeared prominently for some weeks during 2008 on England's Qualifications and Curriculum Development Agency website, provides an extreme example of such rhetoric, but one that perhaps well illustrates the new tendency for educational policy to be framed as a set of common-sense orthodoxies, to which all should aspire.

The curriculum should be treasured. There should be real pride in our curriculum: the learning that the nation has decided to set before its young. Teachers, parents, employers, the media and the public should all see the curriculum as something to embrace, support and celebrate. Most of all, young people should relish the opportunity for discovery and achievement that the curriculum offers. (Qualifications and Curriculum Development Agency 2008)

Such discourses, which seem more at home in a totalitarian state than a modern democracy, will strike a chord with those currently engaged in implementing the new breeds of curricula elsewhere. They are potentially highly damaging to the teacher professional autonomy and the systemic flexibility that the new curricula claim to be promoting. Furthermore, they prop up commonsensical notions of what is right in the curriculum, by undermining the potential for critique. According to Watson,

To criticise such laudable aims would be like giving motherhood and apple pie a good kicking but whose values underpin this? Who says what counts as a responsible citizen? An effective contributor? etc. .... Despite the veneer of self-evident goodness these are not .... unproblematic constructions of self-hood. (Watson 2010, 99)

Curriculum theory provides an antidote to such discourses. It provides the conceptual tools for understanding and critique. As such, it potentially supports the 
development of more informed curriculum policy and more systematic and reflexive approaches to enacting such policy.

\section{Whatever happened to curriculum theory?}

The above question, the title of a curriculum theory seminar, held at the University of Stirling in January 2010 and sponsored by this journal, neatly sums up the second facet of the 'crisis' of curriculum. There is a rich vein of literature in the field of curriculum development, with roots in the early part of the $20^{\text {th }}$ century. For example, one can point to the British tradition of theorizing curriculum. There are: the knowledge-based model articulated by Hirst (1975); Lawton's (1975) sociological cultural invariants model; the critique of Lawton's model, with roots in the 'new sociology of education' (e.g. Whitty 1985); and the school-based, process models advocated by the likes of Stenhouse (1975) and Kelly (1986, 1999). Predating much of this British intellectual activity is the rich North American tradition - prereconceptualisation - of curriculum development, notable work being produced by Bobbitt (2009), Dewey (1938), Tyler (2009) and Taba (1962).

Curriculum studies remains a thriving field of study some parts of the world such as North America, where the reconceptualisation of the field, exemplified by the work of William Pinar (e.g. Pinar et al. 1995) and Michael Apple (e.g. 1995), is prominent. In North America, reconceptualisation was a response to what was claimed to be an earlier crisis - a field of study that had become 'terminally ill or already deceased' (Pinar 2009, 170). However, the movement has attracted criticism for rendering curriculum studies more distant from the day-to-day concerns of schooling and becoming relatively unintelligible to teachers (Hopmann 2010), becoming for example often more concerned with post-structural critique of power relations in educational practices than in curriculum development (Pinar et al. 1995). In continental Europe, there is a vibrant tradition of Didaktik (e.g. Hopmann 2003), which may be seen as fulfilling similar functions as curriculum studies in AngloAmerican education systems.

Curriculum studies has to some extent fallen into abeyance in the United Kingdom since the 1980s (Moore 2006; Priestley and Humes 2010). In part, this may be attributed to the tendency for curriculum policy to become more prescriptive since 
the 1980s. Initiatives such as England's National Curriculum undermined teacher autonomy through prescription of content, and increasingly methods. Consequently, teachers have come to be seen more as technicians implementing preset policy (Ball 2008; Biesta 2010), than as professionals creatively mediating flexible policy frameworks (Osborn et al. 1997).

The decline in curriculum theory in the UK, and the parallel reconceptualisation of the field in North America would appear to have two major implications. The first is the emergence of technical curriculum policy making that is seemingly ignorant of, or at least fails to recognise decades of curriculum development theorising. Scotland's Curriculum for Excellence is a good example of this. I have argued elsewhere (Priestley and Humes 2010) that the model is a mixand-match approach that draws eclectically on multiple, often competing models of curriculum development, and that a consequence of this is the creation of difficult tensions for teachers seeking to make sense of policy. Thus Curriculum for Excellence combines elements from process and outcomes models of curriculum that are viewed as incompatible (Kelly 1999). This creates conflicting starting points for school-based curriculum development (Priestley 2010). The new curriculum is thus ahistorical and atheoretical, and as a result prone to difficult problems in its implementation. Such 'ad hockery' stands in stark contrast to earlier curriculum development in Scotland. For instance, the development of Standard Grade following the Munn Report (Scottish Education Department 1977) was explicitly underpinned by the epistemology developed by Paul Hirst (1974). Whether one agrees or not with the curriculum theory in question, one cannot deny that this particular curriculum was at least theory-informed.

A second issue concerns implementation. This curricular model, with its renewed emphasis on the professional input of teachers as developers of the curriculum, has emerged at a time when capacity for school-based curriculum development is arguably limited as a result of the decline in curriculum studies outlined above. At the meso and micro levels of curriculum enactment, an atheoretical perspective potentially denies local policy makers and practitioners the conceptual tools to make sense of policy, and reconcile it with local needs and contingencies in a manner that is educational. I use the term educational deliberately 
here, as a contrast to curriculum decision-making that is instrumental - for example being based upon the demands of a narrow attainment agenda driven by league tables.

A reinvigoration of curriculum theory is necessary to counter such recent curricular trends. III-thought out curriculum policy, driven by a hotch-potch of competing agendas and ignorant of coherent theoretical underpinnings, has the potential to be highly detrimental to education. The formulation of national curriculum policy requires new thinking, and fresh theorizing. Critical realism offers one way forward, providing powerful conceptual tools, both epistemological and methodological, for addressing educational questions. It has not been widely utilised to date in educational thought, with a few notable exceptions (e.g. Scott 2000, 2010; Wheelahan 2010). There are different currents of thought in the complex terrain of critical realism. This paper draws primarily on the work one theorist, the sociologist Margaret Archer (1988, 1995, 2000), while acknowledging its wider debt to critical realism in general. The remainder of the article sets out the major tenets of critical realism, before concluding with a brief analysis of some of the possibilities that it offers for curriculum theory.

\section{Critical realism}

Critical realism articulates several key concepts which have great relevance when formulating curriculum theory. I provide here a short overview of some of the key ideas, before providing more detail on the aspects of Archer's realist social theory that are especially pertinent to the curriculum. First, critical realism posits a depth ontology. There are two dimensions to this (Elder-Vass 2008a). The first is a conception of three domains of reality: 1] the empirical, or that which is experienced; 2] the actual, or that which occurs (in other words events and entities); and 3] the real, comprising underlying mechanisms with causal properties. The second dimension lies in the concept of stratification of society, with successive layers emerging from those below. Thus, for example, a school is stratified, comprising individuals, social groupings (such as departments) and the school as a whole. In turn, the school may be seen as a sub-stratum of the wider educational system, and in turn the whole of society. Key to this depth ontology is the concept of emergence. Each successive stratum possesses properties not possessed by the individual 
entities that come together to form the emergent whole. Thus, for example, a social group such as a school department will possess certain emergent properties (for example certain forms of power/social influence) not possessed by the individuals within the group, by dint of the relationships that bind it together (see Elder-Vass $2007,2008 b$ for a fuller discussion of these issues).

This brings us to a second key tenet of critical realism, namely that mechanisms and their properties exist independently of our knowledge of them. For instance, social objects, such as social structures, customs and traditions, are real in that they persist in time and space, existing independently of and anterior to the knower, and exerting causative influences on social events and the actions of people (Archer 1995). Conversely, social relations ${ }^{1}$ act to change or preserve existing social objects, as well as leading to the evolution of new cultural, structural and individual forms (Archer 1995; Elder-Vass 2008a, 2008b). The diagram below (figure one), derived from Archer's $(1988,1995)$ social theory, illustrates how a social system might be represented in this way.

\footnotetext{
${ }^{1}$ One might say the same about transactions with the material environment. Indeed, Archer (2000) posits a complex web of relationships with what she terms the social, practical and natural worlds. However, although for the sake of simplicity I will confine the forthcoming discussion to social relations, whilst acknowledging the importance of material transactions in social transformation and reproduction.
} 


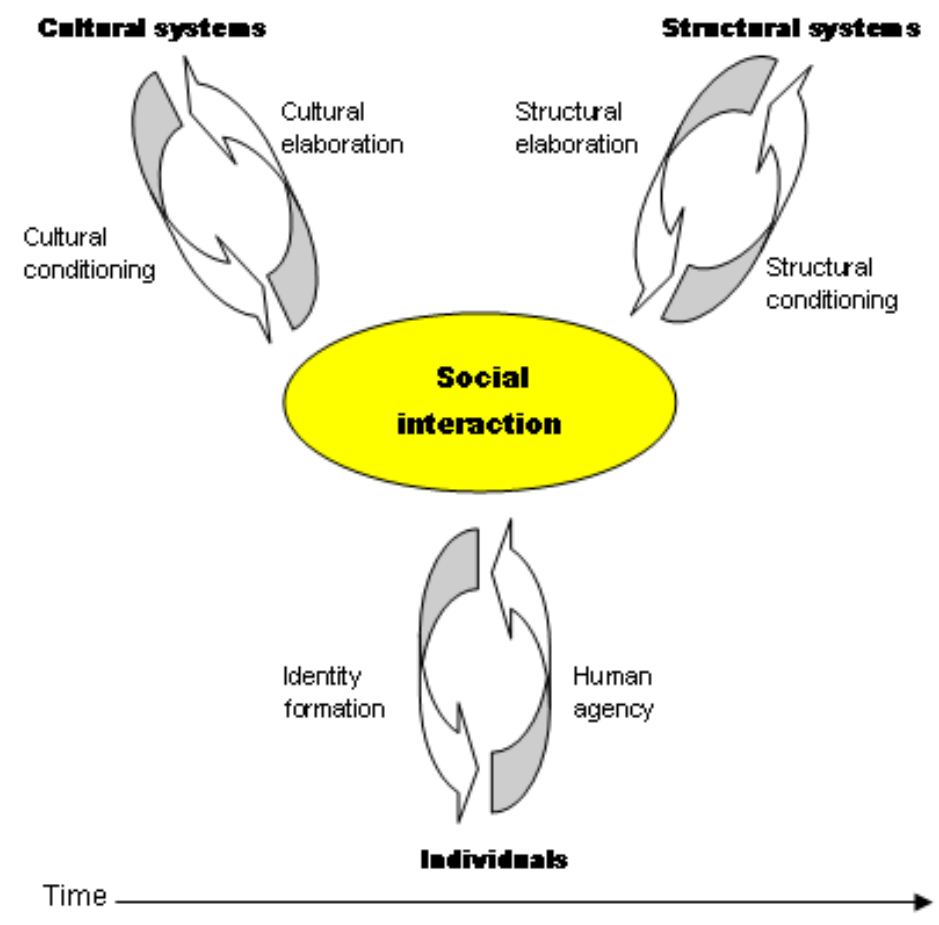

Archer's social theory is somewhat unattractively termed Morphogenesis/Morphostasis (M/M), the terms denoting change and continuity. $\mathrm{M} / \mathrm{M}$ is posited by Archer (2000) as a centrist position that does not privilege the individual over society or vice versa. Moreover, this is not a version of Giddens's (1984) structuration theory, which according to Archer (1988) conflates the two, consequently obscuring the processes that occur when social interaction leads to cultural, structural and individual elaboration. While Giddens claims that social structures are continually instantiated by human action, simultaneously acting back on agency, Archer's notion of analytical dualism provides us with a methodological means of separating (for analytical purposes) these different aspects of social reality. It allows us to disentangle the various aspects that contribute to the unfolding of a given social situation, enabling us to make judgments about the relative causative weight of culture, structure and agency in any given social situation. Archer suggests that the interplay between culture, structure and agency occurs at what she calls the socio-cultural level. It is useful at this point to say a little more about each of these three aspects of social reality. 
According to Archer (1988), the cultural system is made up of cultural forms. Archer uses the term culture to describe beliefs, values, norms, ideas and other kinds of information, rather than in a narrow 'this is the way we do things' sense. Archer $(1988,143)$ posits four propositions in respect of the cultural system:

1. There exist logical relations between the components of the cultural system (e.g. contradiction and coherence).

2. There are causal influences exerted by the cultural system on the sociocultural level.

3. There are causal relationships between groups and individuals at the sociocultural level.

4. The cultural system (and structural system) is elaborated because of sociocultural interaction, modifying current logical relationships and adding new ones.

Archer suggests that there are two types of relations within the cultural system. The first comprises contradictions and complementarities that are logical or epistemic relations, internal to particular cultural forms. The second type comprises social or political contradictions and complementarities that might occur between competing ideational systems or cultural forms. Contradictions are 'site[s] of cultural tension' (Archer 1988, 154), which constitute problem-ridden situations for human actors, leading to social elaboration.

Another aspect of social reality is the structural system. Social structures have been defined variously, by different thinkers. For example, Giddens's (1984) structuration theory views them as rules and resources that govern human behaviour. Critical realism differs from this somewhat deterministic view, but even here there is disagreement amongst different advocates of critical realism. Porpora $(1998,339)$ defines them rather narrowly as the emergent properties of 'systems of human relationships among social positions'. In contrast, Elder-Vass (2008b) suggests that social structures comprise the constituent parts, the relations between them, the emergent whole and the emergent properties of the whole. Nevertheless, despite these definitional differences, critical realists would agree that: 
the causal effects of structure on individuals are manifested in certain structured interests, resources, powers, constraints and predicaments that are built into each position by the web of relationships (Porpora 1998, 344).

Such emergent properties, in combination with cultural forms, provide the material conditions within which human activity occurs, although they do not necessarily determine such activity, given that humans are creative, reflexive and reflective, and have the capacity to act counter to such constraints. As well as providing the context for human activity, structures are modified by the intended and unintended consequences of such activity. The cultural and structural systems pre-exist human activity, but are modified by such activity. In Archer's terms (1995), the emergent properties of structures escape their creators to act back on them. Seen in this way, human agency is an effect of the interplay of the cultural and structural systems something to be achieved, the extent of which will vary for individual actors from one social setting to the next. However, agency is also a cause of further social elaboration. This is a temporal process of successive morphogenetic (change) and morphostatic (continuity) cycles as new cultural, structural and individual properties emerge, and as existing patterns are perpetuated.

Archer (1988) suggests that the cultural and structural systems are parallel but autonomous, interplay between them occurring through socio-cultural interaction. Particular cultural forms and social structures may operate in symbiosis. For example, ideologies relating to accountability in school (cultural forms) enable the persistence of power that is an emergent property of certain roles and systems in schools (social structures), and in turn such roles serve to perpetuate and develop the ideology in question. In combination, the existence of the ideology and the roles and systems might enable and constrain teacher agency, and influence how certain teachers are able to bring to bear particular experiences and values in acting within these constraints.

\section{Critical realism and curriculum theory}

How, then, does such theory apply to the field of curriculum studies? There are clearly possibilities in relation to knowledge and the curriculum, for example deciding what knowledge should be developed by young people in the course of their formal 
education? What content is to be chosen from the vast corpus of human knowledge? Indeed, there is an emerging body of work in this area which draws explicitly explicitly on critical realism (Scott 2010; Wheelahan 2010), although social realist writing (e.g. Moore 2000; Young and Moore 2002; Young 2009) has developed the theme of curriculum and knowledge more extensively. It is fair to say that critical realism merely offers the tool making tools (Balkin 1998) at present for tackling this task, rather than the precise methodological tools themselves, and the work to date complements the work of social realists, rather than setting new directions in theorising. There is work required to apply critical realism to problems of curricular content/knowledge (Wheelahan 2010); however, such an undertaking lies beyond the scope of this paper.

A second area, where critical realism offers enormous potential, is the field of curriculum change and development. Educational change is a field of study that has accrued an enormous amount of literature. Some of this literature relates directly to the types of school-based curriculum development that the emerging curricular forms described earlier appear to be advocating (e.g. Skilbeck 1998). However, critical realism has not been used to any great extent in this field, and offers the potential for fresh perspectives on the thorny issue of curriculum change, both in terms of how policy makers construct policy for change, and in the management of change in schools and local education authorities. The concluding part of this paper offers some reflections on how critical realism may be applied to illuminate issues in the field of curriculum change.

\section{Curriculum change}

Decades of educational change literature has shown how teachers are able to mediate externally initiated innovation through a process of iterative refraction (Supovitz 2008), leading to the reforms being assimilated into current practice (Cuban 1998; Bowe, Ball, and Gold 1992) or even deliberately subverted (Osborn et al. 1997). Part of the problem lies in how innovation is often perceived - as policy to be implemented faithfully. We know that it is inevitable that the cultural forms that comprise policy will mutate as they transmit through the educational system, and factors that impact on this process are highly variable and beyond the control of central policy makers. Thus, the traditional notion of fidelity to the original innovation 
(Cuban 1998) as an evaluative measure of its success becomes suspect. Cuban suggests two additional (or alternative) standards for judging the success of an innovation. The first of these is adaptiveness; put simply, to what extent does an innovation allow practitioners scope for 'inventiveness (and) active problem solving' (Cuban 1998, 459)? In Cuban's view, this criterion is an essential precondition for a fifth measure: longevity. However, this is only part of the picture in evaluating whether changes that accrue from an innovation are genuine changes in social practices or simply strategic responses to yet another new policy, designed to tick the boxes and satisfy the demands of accountability mechanisms without involving too much disruption to existing ways of acting. Research suggests (e.g. Priestley 2011) that one response to externally initiated innovation, is to adopt superficially (for instance in terms of paperwork) while continuing with more established practices. In the light of such possibilities, we should therefore add another criterion, embeddedness, to Cuban's typology. This concerns the extent to which changes prompted in response to innovation are genuine changes in practice.

Supplanting the evaluative notion of fidelity, with forms of evaluation based upon the capacity of actors to engage with innovation, suggests that new ways of viewing and dealing with innovation are necessary. Critical realism, particularly Archer's social theory, provides possibilities for such theorising. The key concepts are emergence and social interaction. They offer possibilities at two linked levels: as methodologies to guide those engaged in change; and as an explanatory approach for those researching change contexts.

As a practical means of managing reform at a school level, critical realism potentially provides methodological tools for engaging with policy. Seen in this way, the major goal of engagement with policy for innovation should be meaningful and constructive forms of emergence. Emergence may be sought as a policy goal in terms of:

- Individual emergence, for example enhanced capacity of teachers to teach.

- Structural emergence, for example the designation of new roles and systems in schools to facilitate the new policy. 
- Cultural emergence, for example the refinement of the policy itself as a result of professional engagement.

The result of such emergence will be the elaboration of the social practices that are the concern of the policy. The medium for such engagement, and for subsequent emergence, is social interaction. The resulting practices may, or may not represent transformation; they will certainly reflect engagement with the policy.

Drawing upon critical realism in this way has various implications. First, it makes a clear distinction between innovation (i.e. the policy for change) and change itself (i.e. the transformation of social practices that might result from engagement with the policy). As such, an innovation might be seen as a new set of cultural forms, migrating into a social setting, where they will be subject to social interaction, and the causal influences of existing social structures, cultural forms and individual capacities. According to Archer (1988), there are three archetypal outcomes of such a process:

1. the new idea supplants the old (morphogenesis);

2. the old ideas are maintained and the new rejected (morphostasis);

3. or, more common, elements of the new merge with elements of the old, leading to a form of morphogenesis (particularly when there are points of consensus as well as contradiction between the old and the new, or where the dissonance between them is not significant enough to merit conflict).

Second, it requires a more flexible approach to designing policy. An acknowledgement that practitioners do, and will mediate policy requires the formulation of policy that takes account of local variation mediated through professional engagement, and the extension of professional trust to practitioners. Third, the quality of engagement is important, if emergence is to be meaningful. This requires time and space for engagement, as well as access to resources. Spaces for interaction may be seen as 'space[s] for emergence' (Osberg and Biesta 2008), within which engagement with new policy is meaningful and sustained, a genuine case of democratic, civic vibrancy (Gleeson and Knights 2008). Fourth, such engagement requires also the development of reflexive positioning by those engaging with new policy. This includes consideration of the big ideas in both the 
policy and in current practice, a clear sense of what is needed for engagement (for example the development of different methods of teaching) and most importantly a clear picture of the contextual factors that might promote or inhibit enactment of the new policy. This might necessitate a situational/contextual audit so that practitioners develop a better understanding on the factors that will impact upon enactment.

The development of methodological tools for the formulation of and engagement with policy is only one potential contribution of critical realism to the field of curriculum change. Additionally, critical realism offers researchers the potential for the development of heuristics for the understanding of change contexts. Archer's social theory developed as a means of explaining change and continuity in social settings. Schools and other educational institutions are complex social organisations. Critical realism offers us epistemological tools for tracking the ebbs and flows of morphogenetic cycles over time, presenting the means for mapping the multifarious networks and assemblages that form the basis of events and entities. Critical realism's depth ontology allows us to infer the existence and nature of the mechanisms that underpin such events and entities. I have provided an example of such an approach elsewhere (Priestley 2011).

\section{Conclusion}

The notion of a crisis in curriculum is disputed amongst academics, particularly those in North America, where the reconceptualised flied is thriving. Nevertheless, a strong current of thought suggests that this crisis is real - in a narrowing or repositioning of the field away from the day to day curricular concerns of schools, and as governments increasingly marginalise curriculum theorists in their development of modern breeds of technical-instrumental curriculum (Wheelahan 2010). The question 'whatever happened to curriculum theory?' may elicit different answers depending on the position of the person answering. I suggest that that there is a dearth of fresh theoretical approaches to the development of national curricula, and including the specification of knowledge/content in those curricula, and especially in terms of understanding the dynamics of educational change. Critical realism thus offers means of revisioning a range of problems that are perhaps only partially understood, or understood in different (often unhelpful) ways. And yet, a good deal more substantive work is required in such an undertaking. 


\section{References}

Apple, M. 1995. Education and Power. London: Routledge.

Archer, M. 1988. Culture and Agency: the place of culture in social theory. Cambridge: Cambridge University Press.

Archer, M. 1995. Realist Social Theory: the morphogenetic approach. Cambridge: Cambridge University Press.

Archer, M. 2000. Being Human: the problem of agency. Cambridge: Cambridge University Press.

Balkin, J.M. 1998. Cultural Software: A Theory of Ideology. London: Yale University Press.

Ball, S.J. 2008. The Education Debate. Bristol: The Policy Press.

Biesta, G.J.J. 2004. Education, accountability, and the ethical demand; can the democratic potential of accountability be regained. Educational Theory, 54: $233-250$.

Biesta, G.J.J. 2009. Good Education in an Age of Measurement. Educational Assessment, Evaluation and Accountability, 21: 33-46.

Biesta, G.J.J. 2010. Good education in an age of measurement: Ethics - politics democracy. Boulder, Co: Paradigm Publishers.

Bobbitt, F. 2009. Scientific Method in Curriculum-Making. In The Curriculum Studies Reader, $3^{\text {rd }}$ edition, eds. D.F. Flinders and S.J. Thornton. 15-21. London: Routledge.

Bowe, R., S. Ball, and A. Gold. 1992. Reforming education and changing schools: Case studies in policy sociology. London: Routledge. 
Cuban, L. 1988. Constancy and change in schools (1880s to the present). In Contributing to Educational Change: perspectives on policy and practice, ed. P.W. Jackson, 85-105. Berkeley: McCutchan.

Cuban, L. 1998. How schools change reforms: redefining reform success and failure. Teachers College Record, 99, 453-477.

Dewey, J. 1938. Experience and Education. New York: Touchstone.

Elder-Vass, D. 2007. Emergence and the realist account of cause. Journal of Critical Realism, 4: 315-38.

Elder-Vass, D. 2008a. Searching for realism, structure and agency in Actor Network Theory. The British Journal of Sociology, 59: 455-473.

Elder-Vass, D. 2008b. Integrating institutional, relational, and embodied structure: An emergentist perspective. British Journal of Sociology, 59: 281-99.

Elmore, R.F. 2004. School Reform from the Inside Out: policy, practice, performance. Cambridge, MA.: Harvard Education Press.

Giddens, A. 1984. The Constitution of Society: outline of the theory of structuration. Cambridge: Polity.

Gleeson, D. and D. Knights. 2008. Reluctant Leaders: an analysis of middle managers' perceptions of leadership in Further Education in England. Leadership, 4: 49-72.

Hirst, P.H. 1974. Knowledge and the Curriculum. London, Routledge.

Hopmann, S.T. 2003. On the evaluation of curriculum reforms. Journal of Curriculum Studies, 35: 459-478.

Hopmann, S. 2010. When the battle's lost and won. Some observations concerning "What ever happened to Curriculum Theory". Paper presented at the LET/CPS seminar, University of Stirling, January 26, 2010. 
Kelly, A. V. 1986. Knowledge and Curriculum Planning. London: Harper and Row.

Kelly, A. V. 1999. The Curriculum: Theory and Practice, $4^{\text {th }}$ edition. London: Sage.

Lawton, D. 1975. Class, Culture and the Curriculum. London: Routledge and Kegan Paul.

LTScotland. 2010. Experiences and Outcomes for Science.

http://www.Itscotland.org.uk/curriculumforexcellence/sciences/outcomes/plane tearth/index.asp (accessed July 15, 2010).

Ministry of Education. 2009. New Zealand Curriculum Update 2: The National

Standards and the New Zealand Curriculum.

http://nzcurriculum.tki.org.nz/Ministry-curriculum-guides/NZC-Updates/NZCupdate-2 (accessed November 11, 2009).

Ministry of Education. 2010. Science Curriculum Achievement Aims and Objectives.

http://nzcurriculum.tki.org.nz/Curriculum-documents/The-New-Zealand-

Curriculum/Learning-areas/Science/Science-curriculum-achievement-aimsand-objectives\#level\%204 (accessed July 15, 2010)

Moore, R. 2000. For Knowledge: Tradition, progressivism and progress in education - reconstructing the curriculum debate. Cambridge Journal of Education, 30: 17-36.

Moore, R. and Young, M. 2001. Knowledge and the Curriculum in the Sociology of Education: Towards and reconceptualisation. British Journal of Sociology of Education, 22: 445-461.

Moore, A. 2006. Introduction. In Schooling, Society and Curriculum, ed. A. Moore, 114. Abingdon: Routledge.

Osberg, D. and Biesta, G. 2008. The emergent curriculum: navigating a complex course between unguided learning and planned enculturation. Journal of Curriculum Studies, 40: 313-328. 
Osborn, M., P. Croll, P. Broadfoot, A. Pollard, E. McNess, and P. Triggs. 1997. Policy into practice and practice into policy: creative mediation in the primary classroom. In Teachers and the National Curriculum, eds. G. Helsby and G. McCulloch, 52-65. London: Cassell.

Pinar, W. 2009. The Reconceptualization of Curriculum Studies. In The Curriculum Studies Reader, $3^{\text {rd }}$ edition, eds. D.F. Flinders and S.J. Thornton. 168-175. London: Routledge.

Pinar, W., W. Reynolds, P. Slattery, and P. Taubman. 1995. Understanding Curriculum. New York: Peter Lang.

Porpora, D. V. 1998. Four concepts of social structure. In Critical Realism: essential readings, eds. M. Archer, R. Bhaskar, A. Collier, T. Lawson, and A. Norrie, 339-355. London: Routledge.

Priestley, M. 2010. Curriculum for Excellence: transformational change or business as usual? Scottish Educational Review, 42: 22-35.

Priestley, M. and W. Humes. 2010. The development of Scotland's Curriculum for Excellence: amnesia and déjà vu. Oxford Review of Education, 36: 345-361.

Priestley, M. 2011. Schools, teachers and curriculum change: a balancing act? Journal of Educational Change, 12: 1-23.

Qualification and Curriculum Development Agency. National Curriculum Aims. http://curriculum.qcda.gov.uk/key-stages-3-and-4/aims-values-andpurposes/aims/index.aspx.

Scottish Education Department. 1977. The Structure of the Curriculum in the Third and Fourth Years of the Scottish Secondary School. Edinburgh, HMSO.

Scottish Executive. 2004. A Curriculum for Excellence: Ministerial Response. Edinburgh, Scottish Executive.

Scott, D. 2000. Realism and Educational Research: new perspectives and possibilities. London: RoutledgeFalmer. 
Scott, D. 2010. Education, Epistemology and Critical Realism. London: Routledge.

Skilbeck, M. 1998. School-Based Curriculum Development. In The International Handbook of Educational Change, Part One, eds. A. Hargreaves, A. Lieberman, M. Fullan, and D. Hopkins, 121-144. London, Kluwer Academic Publishers.

Smyth, J. and G. Shacklock. 1998. Re-Making Teaching: ideology, policy and practice. London: Routledge.

Stenhouse, L. 1975. An Introduction to Curriculum Research and Development. London, Heinemann.

Supovitz, J.A. 2008. Implementation as Iterative Refraction. In The Implementation gap: understanding reform in high schools, eds. J.A. Supovitz and E.H. Weinbaum, 151-172. New York: Teachers College Press.

Taba, H. 1962. Curriculum Development: Theory and practice. New York: Harcourt Brace and World.

Tyler, R. 2009. Basic Principles of Curriculum and Instruction. In The Curriculum Studies Reader, $3^{\text {rd }}$ edition, eds. D.F. Flinders and S.J. Thornton. 69-77. London: Routledge.

Watson, C. 2010. Educational policy in Scotland: inclusion and the control society, Discourse: Studies in the Cultural Politics of Education, 31: 93-104.

Wheelahan, L. 2010. Why knowledge matters in curriculum: a social realist argument. London: Routledge.

Whitty, G. 1985. Sociology and School Knowledge. Curriculum Theory, Research and Politics. London: Methuen.

Young, M. 2008. From Constructivism to Realism in the Sociology of the Curriculum, Review of Research in Education, 32: 1-28. 
Young, M. 2009. Alternative Educational Futures for a Knowledge Society. Socialism and Education.

http://socialismandeducation.wordpress.com/2009/12/06/alternative-

educational-futures-for-a-knowledge-society (accessed on January 1, 2010). 